\title{
Student Research
}

\section{Infant and young child feeding practices amongst children referred to the paediatric outpatient department}

\author{
Capt Devyani Sapra ${ }^{a}$, Surg Capt Sougat Ray ${ }^{b, *}$, Brig A.K. Jindal, YSM ${ }^{c}$, \\ Seema Patrikar ${ }^{d}$ \\ ${ }^{a}$ Medical Officer, 310 Field Hospital, C/o 56 APO, India \\ ${ }^{\mathrm{b}}$ Associate Professor, Dept of Community Medicine, Armed Forces Medical College, Pune 411040, India \\ ${ }^{\mathrm{c} C o m m a n d a n t, ~ M i l i t a r y ~ H o s p i t a l ~ N a s i r a b a d, ~ C / O ~} 56$ APO, India \\ ${ }^{\mathrm{d}}$ Lecturer in Statistics and Demography, Dept of Community Medicine, Armed Forces Medical College, Pune 411040, India
}

\section{A R T I C L E I N F O}

\section{Article history:}

Received 7 March 2013

Accepted 2 April 2014

Available online 22 August 2014

Keywords:

Breastfeeding

Child feeding practices

Exclusive breastfeeding

Infant feeding practices

Infections

\begin{abstract}
A B S T R A C T
Background: Worldwide, sub-optimal breastfeeding still accounts for deaths of 1.4 million children aged less than five years. Optimal infant and young child feeding (IYCF) practices have been recognised as the most important intervention for improving child survival and development. Causal association has been found between exclusive breastfeeding with infection-specific infant morbidity and mortality.

Methods: A cross sectional study was undertaken to assess the IYCF practices among 100 caregivers of children aged less than five years, using a semi-structured questionnaire, attending the Paediatric OPD.

Results: Children from higher income groups were not given colostrum at birth. $57 \%$ mothers started breastfeeding within an hour and $88 \%$ of the mothers admitted to have given prelacteal feed. Healthy complementary food was found to be given by most of the mothers. Prevalence of infections was found to be higher $(p<0.05)$ in children whose birth weight $<2.5 \mathrm{~kg}$ and in bottle fed children.

Conclusion: Traditional beliefs and practices, besides lack of knowledge regarding current feeding recommendations, were found to have played an important role in the feeding practices. Creating an enabling environment for comprehensive nutrition education of mothers by health care providers is required.
\end{abstract}

(C) 2014 Published by Elsevier B.V. on behalf of Director General, Armed Forces Medical Services.

\section{Introduction}

Though since 1990, the under-five mortality rate in India has dropped from more than 100 deaths per 1000 live births to 61 in
2011, but the rate of this reduction is still insufficient to reach the Millennium Development Goal - 4 target of a two-thirds reduction of 1990 mortality levels by the year 2015. 43\% children less than five years were reported to be underweight, $48 \%$ stunted and $20 \%$ wasted. ${ }^{1,2}$ Faulty and sub-optimal infant

\footnotetext{
${ }^{*}$ Corresponding author. Tel.: +91 8390367279.

E-mail address: sougatray@hotmail.com (S. Ray).
}

http://dx.doi.org/10.1016/j.mjafi.2014.04.002

0377-1237/C 2014 Published by Elsevier B.V. on behalf of Director General, Armed Forces Medical Services. 
and young child feeding (IYCF) practices, compounded by maternal undernutrition during pregnancy, low birth weight and repeated episodes of illnesses like diarrhoea and acute respiratory infections are considered to be the key reasons. The period of pregnancy and the first two years of life, is also known as the critical thousand days., ${ }^{3,4}$ On the other hand, early initiation and exclusive breastfeeding have been found to be preventing infant morbidity and mortality. ${ }^{1}$ According to NFHS 3, practices of infant and young child feeding (IYCF) remain poor; with $23.4 \%$ children under 3 years breastfed within $1 \mathrm{~h}$ of birth, $46.3 \%$ children aged 0-5 months exclusively breastfed and $55.8 \%$ children aged 6-9 months receiving solid or semi-solid food and breast milk. ${ }^{2}$

The Indian Academy of Paediatrics in 2010, reviewed IYCF 5 and observed inadequate knowledge of caregivers regarding correct infant and young child feeding, frequent infections, high population pressure, low social and nutritional status of girls and women and sub-optimal delivery of social services to be important preventable barriers. With this background in mind, the present study was undertaken to assess the determinants and barriers of infant feeding practices in under five children attending the Pediatrics OPD.

\section{Material \& Methods}

A cross sectional study was carried out at the Paediatric OPD of a tertiary health care centre from July to Aug 2011 among mothers of children under five years of age, suffering from acute sickness, visiting the OPD for consultation and were willing to participate in the study. The children who came for routine check-ups, growth chart monitoring, immunization and non-infectious diseases were excluded. Written consent of the respondents was taken.

In absence of any previous study in the population, the IYCF indicator for early initiation of breastfeeding as reported in the NFHS 3 (i.e. 23.4\%) was used for calculating the sample size. Considering $95 \%$ confidence level and $10 \%$ absolute precision, the sample size was calculated to be 73 . A total of 100 subjects were studied by systematic sampling procedure using the OPD register. A semi - structured questionnaire was used to assess study subjects' socio-demographic and economic profile. Information regarding birth weight, immunization status, and illness in the past two weeks and on the day of examination was obtained. Breastfeeding practices including bottle feeding and the child's eating habits were assessed. Data entry and statistical analysis were performed using the SPSS windows version 14.0 software.

\section{Results}

Most of the mothers were educated, $14 \%$ of them were working and rest were housewives. $62 \%$ of the children were girls. Most of the children (91\%) had received complete immunisation. Out of 88 respondents who had given prelacteal feed, most of them were from a higher income group (Table 1). Almost all mothers agreed to strong family beliefs as the reason for giving prelacteal feed. 17\% (CI 10.57-25.32) mothers started breastfeeding as late as 02 days. Mothers started complementary feeding late varying from 07 months to 13 months. Foods like mashed dal and rice, mashed seasonal fruits, vegetables and biscuit with milk were given to most of the children. $73 \%$ were given milk whereas rest could not be given milk either because of not being able to afford (15\%) or because the child refused to drink (11\%).

Out of 69 mothers who had a child more than 06 months of age, exclusive breastfeeding till 06 months was carried out by 33 (47.8\%, CI 36.25-59.58). 08 out of 100 children were started with bottle feeding before six months and 06 out of these 08 children $(p<0.05)$ had an infection like pneumonia, diarrhoea and common cold (Table 2). Most common reason for starting bottle feed was insufficient breast milk. $51.68 \%$ of the children were in the low birth weight category $(<2.5 \mathrm{~kg})$. There were 13 preterm babies mostly due to gestational hypertension or IUGR. The mean birth weight for the term babies was $2.48 \mathrm{~kg}$ and that for preterm was $1.68 \mathrm{~kg}(p<0.05)$. The prevalence of the infections was also found to be significantly higher $(p<0.05)$ in children whose birth weight was $<2.5 \mathrm{~kg}$.

\section{Discussion}

This study identified the determinants and barriers of suboptimal breastfeeding and other infant feeding practices in children suffering from an acute illness. The study found that though there is almost universal breastfeeding, exclusive breastfeeding is less than satisfactory. Late initiation of

\section{Table 1 - Distribution of the IYCF practices as per income of the respondents.}

\begin{tabular}{|c|c|c|c|c|c|c|c|c|c|}
\hline \multirow[t]{2}{*}{$\begin{array}{l}\text { Income of } \\
\text { the respondent's } \\
\text { family/month (Rs) }\end{array}$} & \multirow[t]{2}{*}{$\begin{array}{l}\text { Colostrum } \\
\text { given } \\
\left(n^{*}=71\right)\end{array}$} & \multirow[t]{2}{*}{$\begin{array}{c}\text { Initiated } \\
\text { breastfeeding } \\
\text { within } 01 \mathrm{~h} \\
\left(n^{*}=57\right)\end{array}$} & \multirow[t]{2}{*}{$\begin{array}{l}\text { Given anything } \\
\text { just after birth } \\
\quad\left(n^{*}=88\right)\end{array}$} & \multicolumn{5}{|c|}{$\begin{array}{l}\text { Age of child (in month) } \\
\text { when Complementary } \\
\text { feeding started } \\
n^{*}=100\end{array}$} & \multirow[t]{2}{*}{$\begin{array}{l}\text { Exclusive } \\
\text { breast feeding } \\
\text { (till } 06 \mathrm{~m}) \\
\left(n^{*}=33\right)\end{array}$} \\
\hline & & & & $<06$ & 06 & $>06$ & $\begin{array}{c}\text { Not } \\
\text { aware }\end{array}$ & Total & \\
\hline$<5000$ & $22(31)$ & $18(31.6)$ & $25(28.4)$ & $1(33.3)$ & $12(35.3)$ & $4(16)$ & $14(36.8)$ & 31 (31) & $13(39.4)$ \\
\hline $5000-10,000$ & $37(52.1)$ & $29(50.9)$ & $44(50)$ & $2(66.7)$ & $14(41.2)$ & $14(56)$ & $18(47.4)$ & $48(48)$ & $13(39.4)$ \\
\hline$>10,000$ & 12 (16.9) & $10(17.5)$ & 19 (21.6) & 0 & $8(23.5)$ & $7(28)$ & $6(15.8)$ & $21(21)$ & 07 (21.2) \\
\hline Total & 71 (100) & $57(100)$ & $88(100)$ & $3(100)$ & $34(100)$ & $25(100)$ & $38(100)$ & $100(100)$ & $33(100)$ \\
\hline
\end{tabular}

$n^{*}$ denotes total positive response in each parameter.

Values in bracket indicates percentage. 
Table 2 - Infections with respect to birth weight and bottle feed.

\begin{tabular}{|c|c|c|c|c|c|c|c|c|c|}
\hline & \multicolumn{5}{|c|}{ Birth weight } & \multicolumn{4}{|c|}{ Bottle fed before 06 months } \\
\hline & $<2.5 \mathrm{~kg} n^{*}=46$ & $\begin{array}{l}>2.5 \mathrm{~kg} \\
n^{*}=43\end{array}$ & $\begin{array}{c}\text { Not aware } \\
n^{*}=11\end{array}$ & Total & $\begin{array}{c}P \text { value } \\
\text { (Chi square) }\end{array}$ & Yes & No & Total & $\begin{array}{c}P \text { value } \\
\text { (Chi square) }\end{array}$ \\
\hline No Infection & 11 (23.91) & 33 (76.74) & 07 (63.63) & $51(51)$ & $<0.05$ & $02(25)$ & 49 (53.26) & $51(51)$ & $<0.05$ \\
\hline Common Cold & $11(23.9)$ & $1(2.3)$ & 0 & $12(12)$ & & $1(12.5)$ & $11(12)$ & $12(12)$ & \\
\hline Pneumonia & $12(26.1)$ & $1(2.3)$ & $2(18.2)$ & $15(15)$ & & 0 & $15(16.3)$ & $15(15)$ & \\
\hline Diarrhoea & $9(19.6)$ & $3(7)$ & $2(18.2)$ & $14(14)$ & & $1(12.5)$ & $13(14.1)$ & $14(14)$ & \\
\hline $\begin{array}{l}\text { Diarrhoea and } \\
\text { pneumonia }\end{array}$ & $2(4.3)$ & $3(7)$ & 0 & $5(5)$ & & $3(37.5)$ & $2(2.2)$ & $5(5)$ & \\
\hline Measles & $1(2.2)$ & $2(4.7)$ & 0 & $3(3)$ & & $1(12.5)$ & $2(2.2)$ & $3(3)$ & \\
\hline Total & $46(100)$ & $43(100)$ & $11(100)$ & $100(100)$ & & $08(100)$ & $92(100)$ & $100(100)$ & \\
\hline
\end{tabular}

$n^{*}$ denotes total positive response in each parameter.

Values in bracket indicates percentage.

breastfeeding and use of prelacteal feed were other important findings. Use of appropriate complementary feed, however, was satisfactory. The study also revealed that children visiting the Paediatric OPD with any illnesses had certain antecedent causes like low birth weight, preterm, etc.

Initiation of breastfeeding within $1 \mathrm{~h}$ of birth was present in $57 \%$ cases which were higher than the corresponding national (23.4\%) and Maharashtra (52\%) figures of the NFHS $3^{2}$ but less than that of a study ${ }^{9}$ from North India where most of the mothers had initiated breastfeeding (78.8\%) within $24 \mathrm{~h}$ of delivery. However, the use of prelacteal feed was very high (88\%) in our study compared to the corresponding NFHS 3 figures for India (57.2\%). Giving prelacteal feed is a deep-rooted custom in India. Unfortunately, most of these studies have found that the mothers are not aware themselves, that prelacteal feeds could be a source of infection. ${ }^{6}$ In our study too, the mothers agreed to give the prelacteal feed because of the prevailing social custom.

Exclusive breastfeeding was followed by $47.8 \%$ of the mothers in our study compared to the national average of $46.3 \%$ (NFHS 3, 2) and $77.2 \%$ in a rural population. ${ }^{6}$ Also, it was observed that most of the mothers with higher education or from higher income group did not follow the proper breastfeeding practices. Families who can afford cow's milk or formula feed, often introduce bottle feeding before six months perceiving it to be better and healthier than breast milk. ${ }^{7}$ In our study, it was found that $8 \%$ mothers bottle fed their children before 06 months and out of them $75 \%$ had some kind of infection (Table 2). A metanalysis by Jackson $\mathrm{S}$ et al showed an OR of 2.34 (1.42-3.88) associated with lack of exclusive breastfeeding 8 and contracting infection. The proportion of bottle feeding in the present study was however less than that reported by Pandey ${ }^{9}$ et al and Sinhababu ${ }^{3}$ et al, both from rural West Bengal.

Optimal breastfeeding and age appropriate complementary feeding practices, together, can prevent deaths in children under five years by significantly reducing mortality from infections like diarrhoea and pneumonia. ${ }^{5}$ Thick homogenous food, made from locally available preparations, should be introduced at six months while continuing breastfeeding for at least two years. Thus breastfeeding is not weaned but continued till two years. In our study, foods like mashed dal or rice, mashed fruits and vegetables, biscuit with milk were given to the children, implying fairly good knowledge of the types of food to be given. It was also observed that the feeding practices as per IMNCI guidelines ${ }^{10}$ were being followed by most (60-77\%) of the mothers in the study. 34\% mothers in our study started complementary feeding at 06 months and $25 \%$ started later, and rest had started before 06 months of age. An important limitation of the study was that most of the data was captured based on recall of the respondent, hence recall bias cannot be ruled out.

Specific targeted health education by health care providers are needed to be carried out for the pregnant and lactating mothers to protect, promote, and sustain nutritional sustainability in the intergenerational cycle and thereby helping the nation in achieving the MDG 4 and 5 by 2015.

\section{Conflicts of interest}

All authors have none to declare.

\section{Acknowledgement}

ICMR Project Ref ID 2011-02904, Department of Paediatrics, Armed Forces Medical College, Pune.

\section{R E F E R E N C E S}

1. Ministry of Health and Family Welfare. Government of India. Guidelines for Enhancing Optimal Infant and Young Child Feeding Practices. 2013.

2. National Family Health Survey 3, India. Available from: http://www.rchiips.org/nfhs/pdf/India.pdf

3. Sinhababu A, Mukhopadhyay DK, Panja TK, Saren AB, Mandal NK, Biswas AB. Infant and young child feeding practices in Bankura district, West Bengal, India. J Health Popul Nutr. 2010;28(3):294-299.

4. Grantham McGregor S, Cheung YB, Cueto S, Glewwe P, Richter L, Strupp B. Developmental potential in the first 5 years for children in developing countries. Lancet. 2007;369:60-70.

5. Tiwari S. Infant and young child feeding guidelines: 2010 . Indian Pediatr. 2010;47:995-1004.

6. Mahmood SE, Srivastava A, Shrotriya VP, Mishra P. Infant feeding practices in the rural population of north India. J Fam Community Med. 2012;19(2):130-135.

7. Bahl R, Frost C, Kirkwood Betty Rty, et al. Infant feeding patterns and risks of death and hospitalization in the first 
half of infancy: multicentre cohort study. Bull World Health Organ. 2005;83:418-426.

8. Jackson S, Mathews KH, Pulanic D, et al. Risk factors for severe acute lower respiratory infections in children: a systematic review and meta-analysis. Croat Med J. 2013;54(2):110-121.

9. Pandey GK, Hazra S, Vajpayee A, Chatterjee P. Breastfeeding indicators from a rural community in West Bengal. Indian $\mathrm{J}$ Public Health. 1997;41:71-74.
10. India Ministry of Health and Family Welfare. Integrated Management of Neonatal and Childhood Illness. Training Module of Health Workers. New Delhi: Ministry of Health and Family Welfare, Government of India; 2003. Available at: www. nihfw.nic.in/NCHRC/Publication/Guidelines. Accessed 10.02.13. 